\title{
Gastric Emptying Improved Significantly After PRG Compared to Billroth-I Reconstruction: Assessment of Gastric Emptying With a ${ }^{13} \mathrm{C}$-Breath Test
}

\author{
TETSUYA TAKI ${ }^{1}$, YOSHIYUKI HOYA $^{2}$, KOJI NAKADA $^{3}$, MASAHIKO KAWAMURA $^{1}$, TAIZO IWASAKI $^{1}$, \\ KEISHIRO MURAKAMI ${ }^{1}$, TOMOYOSHI OKAMOTO ${ }^{1}$, NORIO MITSUMORI ${ }^{1}$ and KATSUHIKO YANAGA ${ }^{1}$ \\ ${ }^{1}$ Department of Surgery, The Jikei University School of Medicine, Tokyo, Japan; \\ ${ }^{2}$ Department of Surgery, Machida Municipal Hospital, Tokyo, Japan; \\ ${ }^{3}$ Department of Laboratory Medicine, The Jikei University School of Medicine, Tokyo, Japan
}

\begin{abstract}
Background: We advocated the usefulness of pylorus-reconstruction gastrectomy $(P R G)$ to improve quality of life following surgery for gastric cancer. The current study assessed gastric emptying following PRG in comparison with those who underwent conventional Billroth-I (B-I) reconstruction and in healthy controls using $a{ }^{13} C$ breath test. Patients and Methods: The study group consisted of 24 patients who underwent PRG from September 20, 2007 to July 26, 2012 at the Department of Surgery at Daisan Hospital (affiliated with The Jikei University School of Medicine). These patients underwent the 'standard' version of a gastric-emptying study using a ${ }^{13} \mathrm{C}$ breath test at $20.5 \pm 11.8$ months after surgery. During the study, the half gastric-emptying time (T1/2) and gastric retention at 5 min after ingestion (RR5) were measured. The data of the PRG group were compared to those for 26 patients who underwent conventional B-I reconstruction and with a group consisting of 20 healthy controls. Results: RR5 was $69.6 \pm 21.8 \%$ in the patients who underwent $P R G$, $45.3 \pm 28.6 \%$ in those who underwent B-I reconstruction, and $93.7 \pm 5.7 \%$ in healthy controls. T1/2 was $17.0 \pm 13.0 \mathrm{~min}$ in patients who underwent $P R G, 5.9 \pm 4.0 \mathrm{~min}$ in those who underwent B-I reconstruction, and $23.3 \pm 4.9 \mathrm{~min}$ in healthy controls. Gastric emptying was delayed in patients who underwent PRG compared to those who underwent B-I reconstruction (RR5: $p<0.0014, T 1 / 2: p<0.0002$ ), and was comparable to that of healthy controls. Conclusion: Gastric emptying improved significantly after PRG compared to B-I reconstruction, and approached that of healthy controls.
\end{abstract}

Correspondence to: Yoshiyuki Hoya, Department of Surgery, Machida Municipal Hospital, 2-15-41 Asahi-cho, Machida-shi, Tokyo, 1940023, Japan. Tel: +81 427222230, e-mail: hoya@jikei.ac.jp

Key Words: Billroth I, dumping syndrome, pylorus reconstruction, $13 \mathrm{C}$ breath test, gastric emptying.
Typical techniques for reconstruction following distal gastrectomy for gastric cancer consist of Billroth I (B-I), BII, Roux-en-Y (R-Y), and pylorus-preserving gastrectomy (PPG), and each technique has its own advantages and disadvantages. We advocated a technique termed pylorusreconstruction gastrectomy (PRG) that abrogates the disadvantages of B-I to improve quality of life (QOL) following surgery for gastric cancer $(1,2)$. The usefulness of this technique has been described elsewhere $(3,4)$. Briefly, the gastric mucosa is divided $2 \mathrm{~cm}$ distal to the free edge of the seromuscular layer, which is everted and sutured to the edge of seromuscular layer using eight stitches with 3-0 absorbable sutures. The duodenum and the remnant stomach are anastomosed end-to-end in two layers to reconstruct the pylorus. By this anastomotic procedure, the gastric mucosa is inverted like a flap-valve to prevent duodenogastric reflex. PRG is a simple and safe anastomotic technique that retains the virtue of the conventional B-I method but with reduced incidence of remnant gastritis by duodenogastric reflex, dumping syndrome and body weight loss after distal gastrectomy for gastric cancer, and which seems to be effective for a long time $(3,4)$.

The current study used a ${ }^{13} \mathrm{C}$ breath test to assess gastric emptying following PRG in comparison with patients who underwent a B-I reconstruction, and healthy volunteers.

\section{Patients and Methods}

The study group consisted of 24 patients who underwent a PRG from September 20, 2007 to July 26, 2012 at the Department of Surgery at Daisan Hospital (affiliated with The Jikei University School of Medicine) and consented to participate in this study. These patients underwent the gastric-emptying study using a ${ }^{13} \mathrm{C}$ breath test (1) $20.5 \pm 11.8$ months after PRG. During the test, the half gastric-emptying time (T1/2) and the gastric retention rate at $5 \mathrm{~min}$ after ingestion (RR5) were measured (2).

A second group consisted of 26 patients who underwent conventional B-I reconstruction, and a third group of consisted of 20 consecutive healthy controls. T1/2 and RR5 in these groups 
Table I. Patient characteristics.

\begin{tabular}{lccc}
\hline & $\begin{array}{c}\text { PRG } \\
(\mathrm{n}=24)\end{array}$ & $\begin{array}{c}\text { B-I } \\
(\mathrm{n}=26)\end{array}$ & $\begin{array}{c}\text { Controls } \\
(\mathrm{n}=20)\end{array}$ \\
\hline $\begin{array}{l}\text { Age, years } \\
\text { Mean } \pm \text { SD }\end{array}$ & $68.2 \pm 11.4$ & $66.0 \pm 8.48$ & $29.5 \pm 6.9$ \\
$\begin{array}{l}\text { Gender, } \mathrm{n} \\
\text { Male:Female }\end{array}$ & $13: 11$ & $19: 7$ & $16: 4$ \\
$\begin{array}{l}\text { Surgical approach } \\
\text { Open }\end{array}$ & 24 & 16 & - \\
$\quad \begin{array}{l}\text { Laparoscopic } \\
\text { Observation period after } \\
\text { surgery, months } \\
\quad \text { Mean } \pm \text { SD }\end{array}$ & 0 & 10 & \\
$\begin{array}{l}\text { RR5, } \% \\
\text { Mean } \pm \text { SD }\end{array}$ & $20.5 \pm 11.9$ & $37.0 \pm 91.4$ & - \\
$\begin{array}{l}\text { T1/2, min } \\
\text { Mean } \pm \text { SD }\end{array}$ & $69.6 \pm 21.8$ & $45.3 \pm 28.6^{\mathrm{a}}$ & $93.7 \pm 5.7^{\mathrm{b}}$ \\
\hline
\end{tabular}

PRG: Pylorus-reconstruction gastrectomy; B-I: Billroth I gastrectomy; SD: standard deviation; RR5: retention rate at 5 min after ingestion: T1/2: half gastric-emptying time. Significantly different from PRG at: ${ }^{\mathrm{a}} p=0.0014,{ }^{\mathrm{b}} p<0.0001,{ }^{\mathrm{c}} p=0.0002,{ }^{\mathrm{d}} p=0.0343$.

were measured by Kawamura et al. previously (2) at the Department of Surgery, The Jikei University School of Medicine. The current study compared these values to those of patients who underwent PRG.

For study of gastric emptying, the radioisotope method has served as the gold standard (5). However, this method is associated with radiation exposure, requires special facilities such as a gamma camera and a radiation-controlled area, and is expensive (6). In the current study, we evaluated postoperative gastric motility using the ${ }^{13} \mathrm{C}$-acetate breath test, which was proposed in 1993 by Ghoos et al. (5) and has been widely used to investigate abnormal gastric emptying that accompanies various digestive disorders $(2,7)$. In recent years, this method has also been used to evaluate remnant gastric emptying following gastrectomy $(1,2)$. The ${ }^{13} \mathrm{C}$-breath test has several advantages, including noninvasiveness, simplicity, safety, and cost efficiency. Regarding its credibility and quantitative evaluation compared to the radioisotope method, Sanaka et al. reported that the ${ }^{13} \mathrm{C}$-breath test is comparable to the radioisotope method for evaluating gastric emptying quantitatively by applying the Wagner-Nelson analysis to the obtained data $(8,9)$. To our knowledge, we are the third to apply Wagner-Nelson analysis to the ${ }^{13} \mathrm{C}$-breath test in the clinical setting in order to evaluate postoperative gastric motility quantitatively $(2,10)$.

Two hundred milliliters of an enteral formula (Racol; Otsuka Pharmaceutical Co., Narto City, Japan) was mixed with a ${ }^{13} \mathrm{C}$ labeled substance (100 mg of sodium acetate: $\mathrm{CH} 313 \mathrm{COONa}$ ) and ingested over a period of $2 \mathrm{~min}$. To collect exhaled breath, participants were instructed to take a deep breath, hold it for about $5 \mathrm{~s}$, and then to exhale. Two hundred milliliters of exhaled breath were collected $(1,300 \mathrm{ml} \times 2$ specimens prior to ingestion) (Figure 1). Breath was collected a total of 18 times: once prior to ingestion of the test meal and at $0,5,10,15,20,30,40,50,60,75,90,105$, $120,135,150,165$, and $180 \mathrm{~min}$ after ingestion. The percentage of

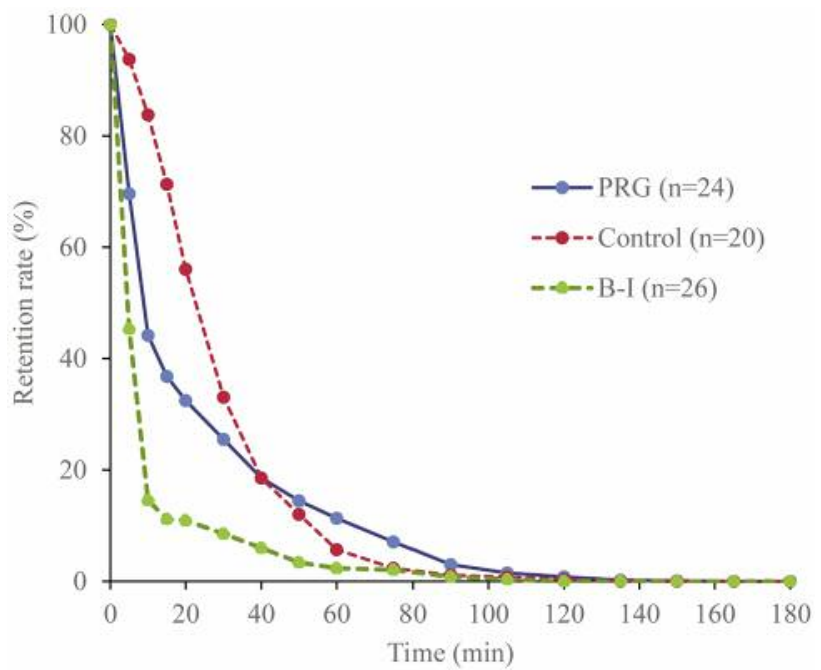

Figure 1. Comparison of gastric-emptying curve among patients who underwent distal gastrectomy with pylorus-reconstruction gastrectomy (PRG), or Billroth-I (B-I) technique, and in healthy controls. Significant acceleration of gastric emptying was observed in the B-I group as compared to that in the PRG and healthy control groups. The gastric retention rate at 5 min after ingestion (RR5) for the PRG group was intermediate between those for the B-I group and healthy controls, in which during the first 10 min it was similar to that of the B-I group, but approximated that of the controls thereafter.

${ }^{13} \mathrm{CO}_{2}$ present in exhaled breath was measured using an infrared spectrophotometer (1). Each measurement after ingestion was subtracted from the measurement prior to ingestion to obtain a $\Delta$ value. Spectrophotometry (POC One; Otsuka Electronics, Tokyo, Japan) was used to continuously measure the difference in the ratio of ${ }^{13} \mathrm{CO}_{2}$ in breath from a large bag containing breath specimens collected prior to and after ingestion (1).

For statistical analysis, the Wilcoxon signed-rank test was used. Data are presented as the mean \pm standard deviation, and differences with $p$-values of less than 0.05 were considered significant. The study was approved by the institutional Ethics Committee of The Jikei University School of Medicine, Tokyo, Japan (20-115 (5405). Each patient enrolled in the study provided written informed consent to participation and use of date.

\section{Results}

RR5 was $69.6 \pm 21.8 \%$ in patients who underwent PRG, $45.3 \pm 28.6 \%$ in patients who underwent B-I reconstruction, and $93.7 \pm 5.7 \%$ in healthy controls. T1/2 was $17.0 \pm 13.0 \mathrm{~min}$ in patients who underwent $\mathrm{PRG}, 5.9 \pm 4.0 \mathrm{~min}$ in patients who underwent B-I reconstruction, and $23.3 \pm 4.9 \mathrm{~min}$ in healthy controls. Gastric emptying was significantly delayed in patients who underwent PRG in comparison with those who underwent B-I reconstruction (RR5: $p<0.0014$, T1/2 (min): $p<0.0002$ ), whose gastric emptying was comparable to that of healthy controls (Table I, Figure 1). 
RR5 of patients who underwent PRG was intermediate between that of those who underwent B-I and the control group, in which the first $10 \mathrm{~min}$ was close to that of the conventional B-I group but approximated that of the control group thereafter.

\section{Discussion}

Surgical treatment is very important for the survival of patients with resectable gastric cancer. However, there seem to be few alternatives among surgeons for the choice of reconstruction procedure after distal gastrectomy.

The preferred reconstruction procedure after distal gastrectomy should minimize postoperative complication and improve QOL (11). Patients may experience various nutritional and functional problems that interfere with their QOL, such as decreased food consumption, body weight loss, and dumping syndrome (12). Deterioration of the reservoir function and rapid emptying of the remaining stomach may be the cause of these problems after distal gastrectomy (13-17).

Currently, B-I and R-Y are the most popular reconstruction procedures after distal gastrectomy (11). B-I is commonly selected after distal gastrectomy for gastric cancer because of the simplicity of the procedure, physiological passage of food in the intestinal tract, and ease of access to the papilla of Vater by endoscope after surgery $(18,19)$. However, B-I anastomosis is associated with duodenogastric reflux, remnant gastritis and reflux esophagitis, due to the absence of the pyloric sphincter which physiologically prevents reflux of duodenal contents into the remnant stomach (20). In addition, the rapid passage of semiliquid food into the duodenum from the stomach results in dumping syndrome (21).

PPG has been reported to attenuate rapid gastric emptying through creation of a substitute stomach by making a jejunal pouch to compensate for the reduced capacity of the gastric reservoir (22). Our pylorus reconstruction is not a complicated procedure and enables complete D2 lymphadenectomy, unlike PPG, and improvement of gastric retention similarly to PPG and jejunal interposition.

We found the degree of remnant gastritis after PRG was lower than that associated with conventional B-I, and the acid concentration after PPG was lower than that after B-I $(3,4)$ Moreover, the proximal side of the modified B-I anastomosis had the appearance of a reconstructed pylorus, and the inverted gastric mucosa was similar to a distal flap-valve $(3,4)$.

RR5 in the early stage after PRG was similar to that afterB-I, indicating that there was no stenosis due to use of the PRG technique, and the late stage of RR5 was similar to that of the control group, showing that there was a degree of food stagnation. We believe that this shows that PRG can improve dumping syndrome.
Therefore, our study demonstrates that our PRG method is superior to conventional B-I in preventing duodenogastric reflex. Moreover, we believe our PRG is a superior in that it overcomes the shortcomings of conventional B-I whilst offering the advantages of the R-Y technique $(3,4)$. The current study demonstrated excellent results after PRG, for which RR5 approximated that of the control group and was significantly better than that of the B-I group.

The limitation of the current study was that the control group were younger than the patients in both B-I and PRG groups. Since there are some reports that gastric emptying tends to be slower in the elderly $(23,24)$, this difference may have influenced our results. Further robust clinical studies and the collection of large-scale data are required. In the future, however, we plan to conduct a survey using the Post Gastrectomy Syndrome Assessment Scale (PGASAS) formulated by the working group Contemplating the Evaluation of Gastric Cancer Following Surgery in Japan (1) to evaluate QOL after gastrectomy.

\section{Conclusion}

Gastric emptying improved significantly after PRG compared to B-I reconstruction, and was comparable to that of healthy controls. Therefore, PRG seems to be a better reconstruction procedure after distal gastrectomy for gastric cancer.

\section{Conflicts of Interest}

The Authors report no proprietary or commercial interest in any product mentioned or concept discussed in this article.

\section{Authors' Contributions}

Critical revision of the article for important intellectual content: $\mathrm{T}$. Taki. Conception and design of the study: Y. Hoya, K. Nakada, T. Okamoto, N. Mitsumori. Collection and processing of data: Y. Hoya, K. Nakada, M. Kawamura, T. Iwasaki, K. Murakami. Final approval of the article: K. Yanaga.

\section{Acknowledgements}

This study was partially supported by the Clinical Research Fund of Daisan Hospital (affiliated with The Jikei University School of Medicine) and a 2013 grant from the Ministry of Education, Culture, Sports, Science, and Technology's Project to Establish Bases to Research the Medical Applications of Stable Isotopes. The Authors thank all the patients whose cooperation made this study possible.

\section{References}

1 Nakada K, Aoyama N, Nakagawa M , Kawasaki N, Shirasaka D, Zai H, Urida S, Kitagawa Y, Koyama S, Shishido T, Kusunoki H, Kato M, Hanyu N, Haruma K and Hongo M: The present and the future in gastric emptying study assessed by ${ }^{13} \mathrm{C}$ 
breath test - with special reference to the standardization of the method, presented at the 44th Annual Meeting of the Japanese Smooth Muscle Society. J Smooth Muscle Res 6: 75-91, 2002. DOI: 10.1540/heikatsukinzashi1997.6.J75

2 Kawamura M, Nakada K, Konishi H, Iwasaki T, Murakami K, Mitsumori N, Hanyu N, Omura N and Yanaga K: Assessment of motor function of the remnant stomach by ${ }^{13} \mathrm{C}$ breath test with special reference to gastric local resection. World J Surg 38: 2898-2903, 2014. PMID: 24934641. DOI: 10.1007/s00268-0142660-6

3 Hoya Y, Taki T, Tanaka Y, Hoshino M, Okamoto T, Kashiwagi $\mathrm{H}$ and Yanaga $\mathrm{K}$ : Usefulness of pyloric reconstruction without compromising curative resection in gastric cancer treatment. J Gastrointest Surg 16: 1102-1106, 2012. PMID: 22392089. DOI: 10.1007/s11605-012-1850-5

4 Hoya Y, Taki T, Watanabe A, Nakayoshi T, Okamoto T, Mitsumori $\mathrm{N}$ and Yanaga $\mathrm{K}$ : Durable flap-valve mitigation of duodeno-gastric reflux, remnant gastritis and dumping syndrome following Billroth I reconstruction. J Gastrointest Surg 20: 772775, 2016. PMID: 26666548. DOI: 10.1007/s11605-015-3022-x

5 Ghoos YF, Maes BD, Geypens BJ, Mys G, Hiele MI, Rutgeerts PJ and Vantrappen G: Measurement of gastric emptying rate of solid by means of a carbon-labeled octanoic acid breath test. Gastroenterology 104: 1640-1647, 1993. PMID: 8500721.

6 Katsube T, Konno S, Murayama M, Yoshimatsu K, Shiozawa S, Shimakawa T, Naritaka Y and Ogawa K: Gastric emptying after pylorus-preserving gastrectomy: assessment using the ${ }^{13} \mathrm{C}$ acetic acid breath test. Hepatogastroenterology 54: 639-642, 2007. PMID: 17523340 .

7 Braden B, Adams S, Duan LP, Orth KH, Maul FD, Lembcke B, Hör $\mathrm{G}$ and Caspary WF: The $\left[{ }^{13} \mathrm{C}\right]$ acetate breath test accurately reflects gastric emptying of liquids in both liquid and semisolid test meals. Gastroenterology 108: 1048-1055, 1995. PMID: 7698571.

8 Sanaka M, Nakada K, Nosaka C and Kuyama Y: The WagnerNelson method makes the ${ }^{13} \mathrm{C}$-breath test comparable to radioscintigraphy in measuring gastric emptying of a solid/liquid mixed meal in humans. Clin Exp Pharmacol Physiol 34: 641-644, 2007. PMID: 17581222. DOI: 10.1111/j.1440-1681.2007.04624.X

9 Sanaka M, Urita Y, Sugimoto M, Yamamoto T and Kuyama Y: Comparison between gastric scintigraphy and the ${ }^{13} \mathrm{C}$-acetate breath test with Wagner-Nelson analysis in humans. Clin Exp Pharmacol Physiol 33: 1239-1243, 2006. PMID: 17184507. DOI: $10.1111 / \mathrm{j} .1440-1681.2006 .04516 . x$

10 Konishi H, Nakada K, kawamura M, Iwasaki T, Murakami K, Mitsumori N and Yanaga K: Impaired gastrointestinal function affects symptoms and alimentary status in patients after gastrectomy. World J Surg 40: 2713-2718, 2016. PMID: 27357933. DOI: $10.1007 / \mathrm{s} 00268-016-3613-\mathrm{z}$

11 Takiguchi S, Yamamoto K, Hirao M, Imamura H, Fujita J, Yano M, Kobayashi K, Kimura Y, Kurokawa Y, Mori M and Doki Y: A comparison of postoperative quality of life and dysfunction after Billroth I and Roux-en-Y reconstruction following distal gastrectomy for gastric cancer: results from a multi-institutional RCT. Gastric Cancer 15: 198-205, 2012. PMID: 21993852. DOI: 10.1007/s10120-011-0098-1

12 Tanabe K, Takahashi M, Urushihara T, Nakamura Y, Yamada M, Lee SW, Tanaka S, Miki A, Ikeda M and Nakada K: Predictive factors for body weight loss and its impact on quality of life following gastrectomy. World J Gastroenterol 23: 4823-4830, 2017. PMID: 28765704. DOI: 10.3748/wjg.v23.i26.4823
13 Jay BS and Burrell M: Iatrogenic problems following gastric surgery. Gastrointest Radiol 20: 239-257, 1977. PMID: 355046.

14 Eagon JC, Miedema BW and Kelly KA: Postgastrectomy syndromes. Surg Clin North Am 72: 445-465, 1992. PMID: 1549803.

15 Donahue PE: Early postoperative and postgastrectomy syndromes, diagnosis, management, and prevention. Gastroenterol Clin North Am 23: 215-226, 1994. PMID: 8070910.

16 Mine S, Sano T, Tsutsumi K, Murakami Y, Ehara K, Saka M, Hara K, Fukagawa T, Udagawa $\mathrm{H}$ and Katai H: Large-scale investigation into dumping syndrome after gastrectomy for gastric cancer. J Am Coll Surg 211: 628-636, 2010. PMID: 20829078. DOI: 10.1016/j.jamcollsurg.2010.07.003

17 Nakada K, Yanaga K, Omura N, Kawamura M, Konishi H, Iwasaki T, Mitsumori N, Hanyu N, Kashiwagi H and Oki T: Improving the quality of life after gastrectomy is the next issue after saving the lives of patients with gastric cancer. Nihon Geka Gakkai Zasshi 113: 12-17, 2012. PMID: 22413550.

18 Hintze RE, Adler A, Veltzke W and Abou-Rebyeh $\mathrm{H}$ : Endoscopic access to the papilla of Vater for endoscopic retrograde cholangiopancreatography in patients with billroth II or Roux-en-Y gastrojejunostomy. Endoscopy 29: 69-73, 1997. PMID: 9101141. DOI: 10.1055/s-2007-1004077

19 Hoya Y, Mitsumori N and Yanaga K: The advantages and disadvantages of a Roux-en-Y reconstruction after a distal gastrectomy for gastric cancer. Surg Today 39: 647-651, 2009. PMID: 19639429. DOI: 10.1007/s00595-009-3964-2

20 Namikawa T, Kitagawa H, Okabayashi T, Sugimoto T, Kobayashi $\mathrm{M}$ and Hanazaki K: Double tract reconstruction after distal gastrectomy for gastric cancer is effective in reducing reflux esophagitis and remnant gastritis with duodenal passage preservation. Langenbeck's Arch Surg 396: 769-776, 2011. PMID: 21448727. DOI: https://doi.org/10.1007/s00423-0110777-8

21 Ishikawa M, Kitayama J, Kaizaki S, Nakayama H, Ishigami H, Fujii S, Suzuki H, Inoue T, Sako A, Asakage M, Yamashita H, Hatono $\mathrm{K}$ and Nagawa $\mathrm{H}$ : Prospective randomized trial comparing Billroth I and Roux-en-Y procedures after distal gastrectomy for gastric carcinoma. World J Surg 29: 1415-1420, 2005. PMID: 16240061. DOI: 10.1007/s00268-005-7830-0

22 Ohya T, Ohwada S, Iesato H, Takeyoshi I, Kawashima Y, Ogawa $\mathrm{T}$, Yokomori T and Morishita Y: Jejunal pouch interposition after pylorus-preserving gastrectomy. J Surg Res 86: 177-182, 1999. PMID: 10534421. DOI: 10.1006/jsre.1999.5710

23 Horowitz M, Maddern GJ, Chatterton BE, Collins PJ, Harding $\mathrm{PE}$ and Shearman DJ: Changes in gastric emptying rates with age. Clin Sci 67: 213-218, 1984. PMID: 6744789.

24 Moore JG, Tweedy C and Christian PE: Effect of age on gastric emptying of liquid-solid meals in man. Dig Dis Sci 28: 340-344, 1983. PMID: 6831997. 